\title{
PEMBERDAYAAN PENGAWAS SEKOLAH DALAM UPAYA MENINGKATKAN KINERJA KEPALA SEKOLAH MENENGAH ATAS NEGERI DI KOTA SINGKAWANG
}

\begin{abstract}
A $1 \mathbf{k ~ a ~ d ~ r i * ~}$
Abstract: The empowerment of supervisors in this reserach is giving the powerful/authority to the school supervisor to do their duty and responsibilities to achieve the purpose. empowerment of supervisors activities are planning, controlling, supervising, evaluating, guiding and developing, reporting and follow up. The objective of this research is to get the whole description about the empowerment of supervisors to increase the principal performance. The results of this research indicated that the empowerment of supervisors have been done well in Singkawang. Most of the school supervisor have been given powerful and authority that suitable with their duty and function; besides they have given education, training, seminar, joined in meeting and workshop. However, the improvement of qualification, competence and supervisor sertification which is needed in the future that suitable with the minister regulation of national education (Permendiknas Nomor 12 Tahun 2007). As well as the principal performance have been done well. The principal have done their duty and responsibilities as educator, manager, administrator, supervisor, leader, inovator, and motivator. The improvement of qualification, competence and sertification head master which is needed in the future that suitable with the minister regulation of national education (Permendiknas Nomor 13 Tahun 2007). The conclusion of this research that; The empowerment of supervisors and principal performance have gone well in Singkawang city. Nevertheless, in the future must done the increase of qualification, competence and sertification especially for school supervison and principal position.
\end{abstract}

\section{Keywords : Empowerment, performance.}

\section{PENDAHULUAN}

Dalam upaya mencapai tujuan pendidikan di suatu satuan pendidikan diperlukan seorang pemimpin sebagai kepala sekolah atau manajer yang mempunyai kapasitas yang memadai baik dari segi kepribadian, kualifikasi, kompetensi serta lulus sertifikasi maupun dari segi akademiknya sesuai dengan standar yang telah ditentukan. Menurut Peraturan Menteri Pendidikan Nasional Republik Indonesia No. 13 Tahun 2007 untuk pengangkatan Kepala Sekolah/Madrasah seseorang wajib memenuhi standar kepala sekolah/madrasah yang berlaku Nasional; yakni harus memenuhi kualifikasi dan kompetensi sebagai kepala sekolah. Menurut Keputusan Menteri Pendidikan Nasional Republik Indonesia Nomor 162/13/2003 tentang Pedoman Penugasan Guru sebagai Kepala Sekolah, pada pasal 9 ayat (2), dijelaskan bahwa tugas dan tanggung jawab kepala Sekolah adalah sebagai; pemimpin, manajer, pendidik, administrator, wirausahawan, pencipta iklim kerja dan penyelia. Kompetensi yang harus dimiliki oleh seorang kepala sekolah/madrasah secara umum; harus memiliki pengetahuan, keterampilan, sikap, performance dan etika kerja sesuai dengan tugas dan tanggung jawabnya sebagai kepala sekolah yang meliputi; kompetensi professional, kompetensi Kepribadian/ personal, kompetensi wawasan kependidikan dan manajerial, kompetensi kewirausahaan, kompetensi supervisi, dan kompetensi sosial. Keberhasilan suatu

\footnotetext{
* Jalan Hansi Gang Pendidikan Kelurahan Sekip Lama RT.05/02 Kecamatan Singkawang Tengah Kota Singkawang Kalimantan Barat.
} 
lembaga pendidikan dalam upaya mencapai tujuan pendidikan selain guru dan kepala sekolah tidak terlepas pula karena adanya pembinaan dari pengawas sekolah yang professional dalam melaksanakan tugasnya, untuk itu dalam pengangkatan dan penempatan seorang pengawas sekolah harus pula memperhatikan kualifikasi, kompetensi dan sertifikasi dari seorang calon pengawas sekolah. Menurut Peraturan Menteri Pendidikan Nasional Republik Indonesia No. 12 Tahun 2007 untuk dapat diangkat sebagai pengawas sekolah/madrasah, seseorang wajib memenuhi standar pengawas sekolah/madrasah yang berlaku secara nasional.

Kalimantan Barat khususnya Kota Singkawang masih tertinggal dalam upaya mencapai tujuan pendidikan nasional, baik pada jenjang pendidikan dasar maupun menengah, yang dapat dilihat dari hasil pelaksanaan ujian nasional pada jenjang satuan pendidikan tersebut. Selain itu Pemerintah Kota Singkawang yang baru terbentuk (pemekaran dari Kabupaten Sambas dan Kabupaten Bengkayang Tahun 2001), pada saat ini masih memusatkan perhatian kepada penuntasan wajib belajar bagi segenap masyarakatnya. Banyak faktor yang terkait dan perlu dibenahi dalam upaya mencapai tujuan tersebut yang merupakan suatu sistem dan sub sistem yang saling terkait diantaranya; Stakeholders yang bertugas dan bertanggung jawab langsung dalam bidang pendidikan seperti; guru, kepala sekolah, pengawas sekolah dan orang tua siswa, termasuk pula masyarakat dan lingkungan sekitar sekolah, Sarana dan Prasarana pendidikan sekolah seperti; gedung sekolah, kurikulum, buku pelajaran, labolatorium, perpustakaan, serta alat dan sarana pembelajaran lainnya. Pengawas sekolah sesuai dengan tugas dan fungsinya selaku pembina di sekolah, dalam melakukan tugas dan tanggung jawabnya harus secara rutinitas, kontinyu, terencana serta terprogram, selain itu melakukan pengawasan aspek administrasi dan manajemen terhadap para kepala sekolah. Pengangkatan dan penempatan pengawas sekolah harus memenuhi standar yang telah ditentukan sehingga berpengaruh dalam pencapaian tujuan pendidikan yang diharapkan. Akibat tingkat kemampuan dan komitmen pengawas sekolah yang dipandang rendah, strategi, pelaksanaan tugas dan tanggung jawab yang dibebankan dan program yang diterapkan dalam upaya meningkatkan kinerja kepala sekolah belum dilaksanakan secara maksimal, maka hal demikianlah yang menarik peneliti untuk melakukan penelitian terhadap pemberdayaan pengawas sekolah.

\section{Kinerja}

Kinerja berasal dari kata job performance atau actual performance yaitu prestasi kerja atau prestasi sesungguhnya yang dicapai seseorang; dari hasil kerja secara kualitas dan kuantitas yang dicapai oleh seseorang pegawai dalam melaksanakan tugasnya sesuai dengan tanggung jawab yang diberikan kepadanya, yang dipengaruhi oleh faktor kemampuan dan motivasi. Pengertian kinerja ini menghubungkan antara prestasi kerja yang dicapai dengan kemampuan dan motivasi yang dimiliki oleh seseorang dalam melaksanakan tugas dan kewajibannya untuk mencapai tujuan organisasi yang telah ditetapkan sebelumnya. Semakin tinggi motivasi seseorang untuk melaksanakan tugas

dan tanggung jawab yang diberikan kepadanya maka semakin kuat dan terarah seseorang dalam upaya mencapai tujuan yang telah ditetapkan. Kinerja menurut Rue and Byars (2004:401), juga diartikan sebagai "performance refers to the degree of accomplishment of the tasks that make up an amployee's job". Kinerja berhubungan dengan tingkat pencapaian tugas yang menunjukkan hasil kerja karyawan. Dari pengertian di atas dapat diartikan bahwa kinerja adalah merupakan hasil kerja yang ditunjukkan oleh seseorang dalam upaya mencapai tujuan organisasi yang telah ditetapkan sebelumnya. 
Untuk mencapai hasil kerja yang maksimal diperlukan seseorang yang dapat menggerakkan semua sumber daya dan dana yang ada secara transparan, akuntabel sehingga dipercaya semua pihak.

Sedangkan menurut Wayne F. Cascio (2003:331) "performance ensures that individual employees or teams know what is expected of them and that they stay focused on effective performance". Sedangkan menurut Mathis and Jakson (2003:339), kinerja memastikan bahwa individu atau tim memahami apa yang diharapkan dari mereka, sehingga mereka bisa fokus terhadap kinerja yang efektif. "Performance is essentially what an employee does or does not do. Employee performance common to most jobs includes the following elements: (1). Quantity of output, (2) Quality of output, (3) timeliness of output, (4) Presence at work and (5) Cooperativeness." Kinerja adalah apa yang dikerjakan karyawan dan apa yang tidak dikerjakan. Kinerja karyawan mencakup elemen-elemen berikut; (1) banyaknya pekerjaan, (2) mutu pekerjaan, (3) batas waktu pencapaian pekerjaan, (4) kehadiran pada pekerjaan dan (5) kerja sama yang terjalin. Sebagai pejabat formal, kepala sekolah diangkat melalui proses, prosedur, dan peraturan yang berlaku. Sebagai manajer, menurut Akdon (2006:167), indikator kinerja adalah ukuran kuantitatif maupun kualitatif untuk dapat menggambarkan tingkat pencapaian sasaran dan tujuan organisasi, baik pada tahap perencanaan (ex-ante), tahap pelaksanaan (on-going) maupun tahap setelah kegiatan selesai. Kinerja seseorang akan produktif apabila anggotanya memiliki keterampilan yang dipersyaratkan dan karakteristik pribadi yang baik serta mendapat dukungan dari manajemen ditambah dengan tersedianya sumber daya yang melimpah. Menurut Zainal Akib (2008:78) bahwa kepala sekolah adalah guru yang diberi tugas tambahan sebagai kepala sekolah pada satuan pendidikan.

Menurut Mulyasa (2004:98), kinerja kepala sekolah dapat diukur dan dinilai melalui tugas dan tanggung jawab yang menjadi kewenangan kepala sekolah yaitu; sebagai Kepala sekolah sebagai edukator, sebagai manajer, sebagai administrator, sebagai supervisor, sebagai leader, sebagai inovator dan kepala sekolah sebagai motivator. Ketika melaksanakan tugasnya tidak semua kepala sekolah dapat melakukan dengan sebaik-baiknya, berbagai kendala dan faktor menjadi penyebabnya, oleh sebab itu diperlukan pengawas sekolah yang kompeten dan profesional untuk membantu dan membina kepala sekolah dalam menghadapi dan memecahkan masalah yang menjadi tugas dan tanggung jawabnya, baik bidang administratif maupun manajerial. Untuk mendapatkan pengawas yang kompeten dan profesional, maka perlu adanya pemberdayaan terhadap pengawas sekolah. Upaya peningkatan kinerja kepala sekolah merupakan tanggung jawab kepala sekolah terhadap Institusi dan masyarakat, oleh sebab itu penilaian harus dilaksanakan secara obyektif, transparan dan dapat dipertanggungjawabkan kepada masyarakat. Penilaian bagi kepala sekolah tidak dinilai sekali saja dalam setahun, akan tetapi perilaku kinerjanya senantiasa diamati dan dicatat yang dalam hal ini dilakukan oleh pengawas sekolah selaku pembina langsung kepala sekolah. Apabila terdapat kesalahan yang

dilakukan oleh kepala sekolah maka pengawas dapat melakukan bimbingan langsung dan catatannya disimpan untuk menjadi pertimbangan penilaian kinerja kepala sekolah di akhir tahun dan dipergunakan sebagai pertimbangan untuk pengangkatan dan penempatan pada periode berikutnya. Apabila penilaian akhir telah diberikan kepada kepala sekolah dan setiap kepala sekolah dapat menerimanya dapat dijadikan acuan untuk; pengangkatan kembali atau mutasi sebagai kepala sekolah, kenaikan pangkat dan jabatan, sebagai umpan balik, pelatihan dan pengembangan kemampuan dan ketrampilan kepala sekolah. 


\section{Pemberdayaan}

Pemberdayaan berasal dari penerjemahan Bahasa Inggris "empowerment" yang juga dapat bermakna "pemberian kekuasaan" karena power bukan sekedar "daya" tetapi juga "kekuasaan", sehingga kata "daya" tidak saja bermakna "mampu" tetapi juga "mempunyai kuasa". Goetsch and Davis (2000:132) mengatakan, "empowerment is employee involvement that matter". Pemberdayaan adalah pelibatan karyawan secara bermakna. Pemberdayaan adalah suatu upaya atau proses untuk menumbuhkan kesadaran, kemauan dan kemampuan dalam mengenali, mengatasi, memelihara, melindungi dan meningkatkan kesejahteraan mereka sendiri. Menurut Oakley dan Maraden (2003:349) bahwa konsep pemberdayaan mengandung dua kecenderungan yakni: Pertama, menekankan pada memberikan dan mengarahkan sebagian power (kekuasaan, kekuatan, kemampuan atau daya) kepada orang lain, agar orang tersebut lebih berdaya. Kedua, menekankan pada menstimulasi, mendorong atau memotivasi individu agar mempunyai kemampuan atau keberdayaan. Dengan demikian terdapat dua dimensi utama yang dapat mempengaruhi proses pemberdayaan terhadap pengawas sekolah agar dapat melaksanakan tugas dan tanggung jawabnya secara profesional yaitu dimensi kemampuan (ability) dan motivasi (motivation).

Pemberdayaan pengawas sekolah merupakan pemberian kepercayaan tugas dan tanggung jawab kepada pengawas sekolah yang harus benar-benar dilaksanakan sepenuhnya dan dipilih dari guru atau kepala sekolah yang benar-benar mampu melaksanakannya, mengetahui dan dapat memecahkan segala permasalahan yang dihadapi oleh kepala sekolah serta telah memenuhi kualifikasi akademik maupun personal, lulus uji kompetensi dan sertifikasi pengawas yang dilaksanakan oleh lembaga pendidikan yang berwewenang. Menurut Keputusan Menteri Negara Pendayagunaan Aparatur Negara No. 18 Tahun 1996. Tanggung jawab pengawas sekolah adalah: melaksanakan pengawasan penyelenggaraan pendidikan di sekolah sesuai dengan penugasannya serta meningkatkan kualitas pembelajaran dan hasil belajar serta bimbingan peserta didik dalam rangka mencapai tujuan pendidikan. Dengan demikian tugas pokok pengawas sekolah adalah memantau, menilai, mensupervisi, membina dan melaporkan kinerja guru dalam pembelajaran dan kinerja kepala sekolah dalam mengelola pendidikan. Fungsi pengawas sekolah adalah sebagai mitra guru, inovator,konselor, motivator, kolaborator, asesor, evaluator, dan konsultan bagi guru dan kepala sekolah.

Sedangkan wewenang pengawas sekolah adalah: memilih dan menentukan metode kerja untuk mencapai hasil yang optimal dalam melaksanakan tugas dengan sebaik-baiknya sesuai dengan kode etik profesi, menetapkan tingkat kinerja kepala sekolah dan

tenaga lain yang diawasi serta faktor-faktor yang mempengaruhi serta menentukan dan atau mengusulkan program pembinaan serta melakukan pembinaan.

\section{METODE}

Tempat penelitian ini dilaksanakan di Kantor Dinas Pendidikan Kota Singkawang dan Sekolah Menengah Atas Negeri di Kota Singkawang Provinsi Kalimantan Barat. Ada 2 orang pengawas sekolah di SMA Kota Singkawang dan sepuluh (10) SMA Negeri di Kota Singkawang, yang akan dijadikan populasi sekaligus sebagai sampel dalam penelitian ini. waktu Penelitian dilaksanakan selama lima bulan, dimulai dari Januari 2009 s/d Mei 2009. Pendekatan yang digunakan dalam penelitian ini adalah pendekatan 
deskriptif. Pada penelitian ini dikumpulkan data secara langsung pada konteks terjadinya proses pelaksanaan tugas di sekolah, sumber datanya secara langsung, latar penelitian tidak dimodifikasi dan peneliti langsung sebagai instrumen kunci. Instrumen yang akan digunakan adalah pedoman wawancara, lembar observasi, dokumentasi dan angket. Proses analisis data menggunakan pendekatan deskriptif yang menempatkan dan menyesuaikan dengan masalah, sehingga menemukan konsep-konsep baru.

\section{HASIL DAN PEMBAHASAN}

Berdasarkan data yang peneliti dapatkan diperoleh gambaran bahwa, pengawas sekolah di Kota Singkawang berjumlah 13 orang yang terdiri dari 2 orang pengawas SMA, 1 orang pengawas SMK, 7 orang pengawas TK-SD, 2 orang pengawas SMP, dan 1 orang pengawas SLB, yang memenuhi kualifikasi pendidikan (S2) hanya 1 orang. Adapun hasil penelitian tentang pengawas sekolah dapat dideskripsikan sebagai berikut: Dalam hal pengangkatan Pengawas Sekolah Menengah Atas (SMA) Negeri di lingkungan kerja Dinas Pendidikan Kota Singkawang dipertimbangkan dari kepala sekolah SMA yang berprestasi serta memperhatikan kualifikasi yang telah ditetapkan Peraturan Menteri Pendidikan Republik Indonesia No. 12 Tahun 2007, yakni; pendidikan terakhir yang harus dimiliki oleh pengawas sekolah minimal magister (S2) kependidikan dengan berbasis sarjana (S1) dalam rumpun mata pelajaran yang relevan pada perguruan tinggi terakreditasi. Namun dalam hal ini karena tidak tersedianya personil atau sumber daya manusia (SDM) yang memiliki ijazah magister (S2) kependidikan dengan berbasis sarjana (S1) dalam rumpum mata pelajaran yang relevan di Kota Singkawang. Untuk memenuhi kebutuhan akan pentingnya kedudukan, tugas dan tanggung jawab kepengawasan dalam satuan pendidikan, maka diambil kebijakan oleh Pemerintah Kota Singkawang melalui Kepala Dinas Pendidikan Kota Singkawang dan Badan Kepegawaian Daerah (BKD) pengangkatan pengawas sekolah dari kepala sekolah yang memiliki prestasi dalam melaksanakan tugas dan tanggung jawabnya selama menjabat sebagai kepala sekolah meskipun tidak memiliki ijazah magister (S2) Non kependidikan serta sarjana (S1) kependidikan.

Sebagaimana yang dikemukakan oleh Kepala Dinas Pendidikan Kota Singkawang bahwa; pengangkatan pengawas sekolah pada setiap satuan pendidikan, berasal dari kepala sekolah yang berprestasi dalam menjalankan tugas dan kewajibannya sebagai Kepala Sekolah dengan pengalaman kerja lebih dari 4 tahun, memiliki pengalaman mengajar lebih dari 8 tahun, diutamakan calon pengawas sekolah berusia di bawah 50

tahun, namun dalam hal ini ada kebijakan Pemerintah Kota Singkawang, meskipun memiliki usia telah lebih dari 50 tahun dapat diangkat sebagai pengawas sekolah, apabila memiliki prestasi dan kinerja yang sangat baik dalam melaksanakan tugas dan tanggung jawab sebelumnya. Sejalan dengan Kepala Dinas Pendidikan Kota Singkawang, hal serupa juga dikemukakan oleh Kepala Bidang Administrasi (Tata Usaha) dan Kepala Bidang ketenagaan Dinas Pendidikan Kota Singkawang bahwa; pengangkatan pengawas sekolah di Kota Singkawang sampai saat ini tidak melalui uji kompetensi dan atau pendidikan dan pelatihan fungsional pengawas pada lembaga yang ditetapkan pemerintah. Dalam hal ini calon pengawas sekolah diangkat berdasarkan penilaian hasil kerja yang dilaksanakan selama menjabat sebagai kepala sekolah dalam menjalankan tugas dan tanggung jawabnya. Penilaian dilakukan oleh Kepala Dinas Pendidikan Kota Singkawang, yang selanjutnya calon pengawas sekolah diusulkan kepada Wali Kota Singkawang melalui Badan Pertimbangan Jabatan Kepegawaian Daerah, untuk ditetapkan sebagai pengawas sekolah di salah satu wilayah 
Kecamatan di Kota Singkawang. Dalam upaya pemberdayaan pengawas sekolah, setelah pengawas sekolah diangkat diberikan pendidikan dan pelatihan tentang kepengawasan pada lembaga yang ditetapkan oleh pemerintah, salah satunya yang terdapat di Kalimantan Barat adalah Lembaga Penjaminan Mutu Pendidikan (LPMP) Kalimantan Barat di Pontianak. Mengenai sertifikasi pengawas sekolah, pada tahun ini sedang diproses dengan mengumpulkan dokumen portofolio dan apabila tidak lulus akan mengikuti pendidikan dan pelatihan kepengawasan yang dilaksanakan oleh lembaga yang ditetapkan pemerintah.

Dalam hal penempatan pengawas sekolah, diperoleh informasi bahwa penempatan pengawas sekolah berdasarkan kepada kemampuan dan keterampilan/keahlian serta prestasi kerja yang dimiliki oleh pengawas sekolah serta informasi tentang pemberdayaan pengawas dalam melaksanakan tugas-tugas dan tanggung jawab pengawas sekolah di lingkungan Dinas Pendidikan Kota Singkawang.

Dalam menjalankan tugas dan tanggung jawabnya pengawas sekolah selalu menyusun program kerja dan membuat jadwal kegiatan, tidak merencanakan namun selalu mengikuti pendidikan dan pelatihan, seminar, workshop yang dilaksanakan oleh Lembaga Penjaminan Mutu Pendidikan Kalimantan Barat di Pontianak atau lembaga lain yang ditunjuk oleh Pemerintah, memberikan pendidikan dan pelatihan, seminar atau workshop bagi kepala sekolah di Kota Singkawang sesuai dengan perencanaan dan program kerja Dinas Pendidikan Kota Singkawang maupun melalui musyawarah kerja kepala sekolah atau Asosiasi Pengawas Seluruh Indonesia Kota Singkawang.

Dalam upaya pemberdayaan pengawas sekolah, pengawas sekolah diberikan kewenangan untuk dapat selalu menjamin standar mutu pendidikan, mengawasi penerimaan siswa baru, mengawasi pelaksanaan ujian sekolah, mengikuti kegiatan rapat sekolah dan selalu menjalin hubungan kerja sama yang harmonis antara sekolah dan masyarakat, mengawasi program pengembangan sekolah serta membantu pelaksanaan manajemen kepala sekolah.

Dalam menjalankan tugas dan tanggung jawabnya sebagai supervisor, pengawas sekolah dibekali dengan metode, teknik dan prinsip-prinsip supervisi, dapat dan mampu menyusun metode kerja dan instrumen supervisi untuk mensupervisi kinerja kepala sekolah dan pelaksanaan kurikulum yang mengacu kepada standar kurikulum nasional.

Pengawas sekolah selalu mengaktifkan kegiatan antar sekolah binaan (MKKS), melaksanakan kegiatan in service training bagi kepala sekolah serta mampu mensupervisi administrasi yang dilaksanakan oleh kepala sekolah.

Pemberdayaan pengawas sekolah dalam upaya meningkatkan kinerja kepala sekolah dapat berbentuk penilaian hasil kerja kepala sekolah, dalam hal ini meliputi pula penyelenggaraan inovasi/pengembangan sekolah, mengadakan akreditasi sekolah dan pengadaan sumber daya pendidikan, serta menilai kemajuan pendidikan. Penilaian ini dilaksanakan setiap saat dalam bentuk catatan - catatan bagi pengawas sekolah tentang perkembangan dan kemajuan hasil kerja kepala sekolah untuk dipertimbangkan setiap tahun bagi peningkatan prestasi sekolah dan peningkatan mutu dan kualitas di setiap satuan pendidikan.

Upaya pemberdayaan pengawas sekolah dalam hal ini; membina kepala sekolah dalam mengelola pendidikan di setiap satuan pendidikan, membentuk tim kerja (Team Work) dalam upaya meningkatkan kinerja kepala sekolah, melaksanakan penelitian pendidikan, mampu menulis karya ilmiah (KTI) atau mengadakan penelitian tindakan 
sekolah (PTS), berupaya meningkatkan kesejahteraan kepala sekolah dan aktif dalam APSI.

Setiap pengawas sekolah selain harus mampu melaksanakan tugas dan tanggung jawabnya sebagai bentuk pemberdayaan pengawas sebagaimana dikemukakan di atas, Pengawas Sekolah juga harus mampu membuat laporan hasil dari pelaksanaan tugas dan tanggung jawab yang dibebankan kepadanya dengan obyektif dan akuntabel serta mengadakan tindak lanjut untuk program pengawasan selanjutnya ke arah yang lebih baik dan berkualitas.

Dari penelitian tentang kinerja kepala sekolah diperoleh data hasil wawancara sebagai berikut: dalam hal pengangkatan kepala sekolah, calon kepala sekolah diseleksi diantara guru yang memiliki kualifikasi antara lain; memiliki kualifikasi akademik sarjana (S1) atau diploma empat (D-IV) kependidikan atau non kependidikan pada perguruan tinggi yang terakreditasi, pada waktu diangkat sebagai kepala sekolah berusia setinggi-tingginya 56 tahun dan memiliki pengalaman mengajar sekurangkurangnya 5 tahun menurut jenjang sekolah masing-masing serta memiliki pangkat serendah-rendahnya III/c bagi Pegawai Negeri Sipil (PNS), berstatus sebagai guru SMA dan memiliki sertifikat pendidik sebagai guru SMA, diangkat sebagai pelaksana tugas (Plt) di satuan pendidikan minimal selama 6 bulan, yang kemudian dapat dikukuhkan sebagai kepala sekolah definitif setelah dipandang mampu untuk menjabat sebagai kepala sekolah.

Dalam hal penempatan kepala sekolah disesuaikan dengan kualifikasi, kompetensi serta kemampuan yang dimiliki setiap kepala sekolah, bagi kepala sekolah yang baru diangkat diberikan jabatan sebagai pelaksana tugas (Plt) dalam waktu tertentu dan bagi kepala sekolah yang telah melaksanakan tugasnya sebagai kepala sekolah satu periode dapat diangkat kembali pada sekolah lain, bagi yang berprestasi dapat diangkat dan ditempatkan di sekolah yang lebih besar, bagi yang tidak menunjukkan prestasinya diangkat dan ditempatkan di sekolah yang lebih kecil atau diberhentikan sebagai kepala sekolah untuk dikembalikan kepada tugas pokok semula sebagai guru.

Bagi kepala sekolah yang telah menjabat sebagai kepala sekolah satu periode (4 tahun) dan mempunyai prestasi yang sangat memuaskan, dapat diperpanjang ke periode

berikutnya sebagai kepala sekolah di sekolah yang sama (periode II) dan atau mutasi ke tipe sekolah lebih besar, dipromosikan ke jabatan Pengawas sekolah atau jabatan struktural dengan memperhatikan peraturan yang berlaku dan atau dibebaskan sebagai kepala sekolah untuk melaksanakan tugas sebagai guru secara penuh.

Bagi kepala sekolah yang telah menjabat sebagai kepala sekolah pada periode II dapat diperpanjang ke periode III dan atau mutasi ke sekolah lain dengan tipe lebih tinggi atau sama, dipromosikan ke jabatan pengawas sekolah atau jabatan struktural dengan memperhatikan peraturan yang berlaku dan atau dibebaskan dari tugas tambahan sebagai kepala sekolah, untuk melaksanakan tugas sebagai guru secara penuh.

Bagi kepala sekolah yang telah melaksanakan jabatan kepala sekolah pada periode III dapat dipromosikan untuk jabatan struktural atau pengawas sekolah sesuai dengan peraturan yang berlaku, atau dibebaskan dari tugas tambahan sebagai Kepala Sekolah, dengan melaksanakan tugas sebagai guru secara penuh.

\section{PENUTUP}


Kesimpulan. Pembagian tugas dan fungsi serta kewenangan yang jelas bagi jabatan pengawas sekolah dalam melaksanakan tugas dan tanggung jawabnya, peningkatan kompetensi, kemampuan dan keterampilan pengawas sekolah, serta sertifikasi bagi Pengawas Sekolah merupakan kunci keberhasilan pemberdayaan pengawas sekolah dalam upaya meningkatkan kinerja kepala sekolah. Dengan memberikan kekuasaan dan kewenangan sesuai dengan tugas dan tanggung jawab sepenuhnya kepada pengawas sekolah akan meningkatkan kinerja kepala sekolah yang memimpin satuan pendidikan. Apabila pengangkatan pengawas sekolah berdasarkan kualifikasi, kompetensi dan sertifikasi serta diberikan kewenangan sepenuhnya untuk melaksanakan tugas dan tanggung jawabnya maka diharapkan kinerja kepala sekolah akan meningkat. Penilaian dan pembinaan terhadap kepala sekolah dengan terencana, terprogram, kontinyu, akuntabel, transparan, jujur dan obyektif merupakan bentuk pemberdayaan pengawas sekolah dalam upaya meningkatkan kinerja kepala sekolah.

Saran. Agar pengawas sekolah memenuhi kualifikasi sesuai dengan peraturan yang telah ditetapkan, diberikan kesempatan kepada pengawas sekolah/calon pengawas sekolah dan kepala sekolah/calon kepala sekolah yang memenuhi kriteria tertentu untuk mengikuti pendidikan sesuai dengan kualifikasi yang telah ditetapkan. Pascasarjana ( S2 ) kependidikan bagi pengawas sekolah/calon pengawas sekolah, sarjana (S1) kependidikan bagi kepala sekolah/calon kepala sekolah dengan memberikan bea siswa atau bantuan biaya pendidikan secara bertahap dalam jangka waktu yang telah ditentukan. Perlu adanya Peraturan Daerah tentang pengangkatan pengawas sekolah dan kepala sekolah di Kota Singkawang. Peranan kepala sekolah sebagai manajer perlu pembenahan dan ditingkatkan, seperti pengelolaan keuangan, manajemen personil, kurikulum, maupun manajemen sarana dan prasarana, pemahaman terhadap tugas, proses administrasi dan supervisi. Pengangkatan kepala sekolah hendaknya berpedoman kepada Peraturan Menteri Pendidikan Nasional Republik Indonesia No. 13 Tahun 2007 tentang Standar Kepala Sekolah/Madrasah. Penempatan kepala sekolah hendaknya mengacu kepada Keputusan Menteri Pendidikan Nasional Republik Indonesia No. 162/U/2003, tentang Pedoman Penugasan Guru sebagai Kepala Sekolah. 


\section{DAFTAR RUJUKAN}

Akdon. Strategic Manajement For Educational Management, Manajemen Strategik Untuk Manajemen Pendidikan. Alfabeta, 2006.

Akib, Zainal. Pedoman Pemilihan Guru Berprestasi, Kepala Sekolah Berprestasi, Pengawas Berprestasi. Bandung: CV Yrama Widya, 2008.

Cascio, Wayne F. Managing Human Resoures, Sixth Edition, USA: McGraw-Hill, 2003.

Dwidjowijoto, Randy R. Wrihatnolo Riant Nugroho. Manajemen Pemberdayaan Sebuah Pengantar dan Panduan Untuk Pemberdayaan Masyarakat. Jakarta: PT.Elex Media Kumputindo Kelompok Gramedia, 2007.

Goetsch, David L. and Stanley B. Davis. Quality Manajement Introduction to Total Quality Manajement for Production. Processing and Service Third Edition. New Jersey: Prentice Hall International, 2000.

Mangkunegara, A.A.Anwar Prabu. Manajemen Sumber Daya Manusia. Bandung: PT. Remaja Rosda Karya, 2005.

Mathis, Robert L. and John H. Jackson. Human Resource Management. Tenth Editions. USA: Thomson South Western, 2003.

Rivai, Veithzal. Kepemimpinan dan Prilaku Organisasi. Jakarta: PT. Raja Grafindo Persada, 2004.

Rue, Leslie W and Lioyd Byars. Management. Eighth Edition. USA: Mc Graw-Hill, 2000.

Soekijo, Notoatmojo. Promosi Kesehatan dan Ilmu Prilaku. Jakarta: PT. Rineka Cipta, 2007. 